\title{
HIGH-SPEED VIDEO RECORDINGS OF LIGHTNING, ELECTRIC FIELDS AND HIGH-ENERGY DETECTIONS DURING THUNDERSTORMS IN CATALONIA SPAIN
}

\author{
J. Montanyà ${ }^{1}$, O. van der Velde ${ }^{1}$, D. Romero ${ }^{1}$, N. Pineda ${ }^{2}$, H.D. Betz ${ }^{3}$, V. March ${ }^{1}$ and G. Solà ${ }^{1}$ \\ ${ }^{1}$ Electrical Engineering Department, Technological University of Catalonia, Terrassa (Barcelona), Spain \\ ${ }^{2}$ Meteorological Service of Catalonia, Barcelona, Spain \\ ${ }^{3}$ Physics Department, University of Munich, Garching, and nowcast GmbH, Munich, Germany
}

\begin{abstract}
High-speed video recordings of natural lightning flashes show amazing details of this phenomenon. The paper summarizes the results of the 2009 measurement campaign where the combination of electric fields, total lightning, high-energy detections and high-speed videos provided a valuable data. The paper describes the visible differences between the recorded negative, positive and upward cloudto-ground flashes. Thanks to the precise time synchronization of each video frame we investigated which processes are detected by the lightning location networks (VHF and VLF). We suggest that the VHF interferometer network detects mostly those processes of intra-cloud flashes where substantial charge is transferred during few milliseconds. The study of the detections of intra-cloud events provided by the VLF network were related to high and fast (less than a millisecond) charge transfers within the cloud that saturated the camera in the same manner as return strokes in cloud-to-ground flashes. In other hand, the paper discusses the high-energy detections related to a very close cloud-to-ground lightning flash.
\end{abstract}

\section{INTRODUCTION}

The future ASIM mission by ESA will provide $\mathrm{x} / \mathrm{y}$ rays detections from space to investigate the origins of the Terrestrial Gamma-ray Flashes (TGF) and its possible links with transient luminous events (TLE). In order to support the future space observations we are setting up ground infrastructure located in the Ebro Valley region and Pyrenees (2009, we carried out our first observation north-eastern of Spain). At the end of 2008, and during campaign in order to acquire experience to support the future ASIM mission. From January 2008 to February 2009 we focused on the observation of TLE's with an intensified high-speed camera instrument [1]. After, from June 2009 to October 2009 we focused our efforts on recording lightning at high-speed $(10000$ fps $)$ simultaneously with close vertical electric fields and $\mathrm{x} / \mathrm{gamma}$ rays detections. Lightning flashes were recorded during 13 thunderstorm episodes located at 7 different sites corresponding to the north, center and south of Catalonia. More than 60 videos were gathered but only 41 are adequate for analysis. The paper resumes those results related to the observed lightning flashes.

High-speed videos of natural lightning at several thousands of frames per second provided useful information about lightning processes (e.g. [2-5]). On the other hand, video recordings of lightning have been used for the evaluation of lightning location networks (e.g.[67]). The paper first highlights the characteristics of the different observed types of lightning. Then, since every video frame is GPS time synchronized it allows comparing with single IC VHF sources of the XDDE [8] and the detections provided by the LINET [9]. Since both networks operate with different detection technique and different wavelengths the comparison with what is displaying in every video frame provides a valuable knowledge about what each network is detecting. This is presented in section 4 . At the end, the paper includes a brief discussion about the high energy detections related to natural lightning.

\section{DATA}

A high-speed camera able to record video at rate of $10100 \mathrm{fps}$ with 640x480 pixel resolution was adapted for portable operation. Every video frame was time stamped with an accuracy of $1 \mu \mathrm{s}$ using GPS time. This time resolution allows fine comparison between video and lightning detections provided by two networks: the Catalan Lightning Location Network (XDDE) and the European network LINET. At that time the XDDE [7] was composed by two VHF interferometers LS8000 type plus two SAFIR 3000 type. In the case of LINET [9] it had nine sensors in Spain which were connected with the other ones in Europe.

In addition to the video records, vertical electric fields were measured by means of a flat plate antenna located just at ground level. Moreover, a 76x76 mm $\mathrm{NaI}(\mathrm{Tl}) / \mathrm{PMT}$ detector was used to measure high energy emissions from lightning. The schematic of the system is 
displayed in figure 1.

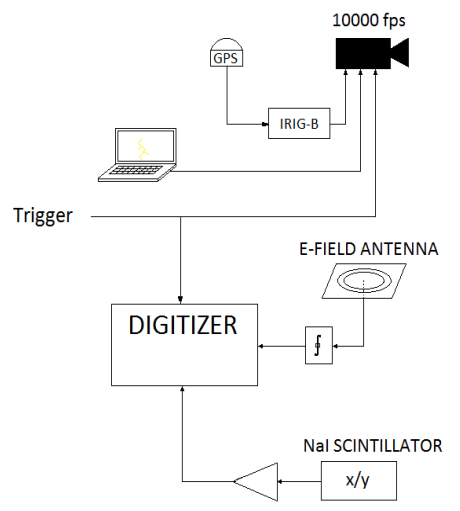

Figure 1. Schematic of the instruments used during the 2009 campaign.

\section{GENERAL CHARACTERISTICS OF OBSERVATIONS}

High-speed video records of lightning revealed impressive details, especially those related to leader processes, M-components, etc. (e.g. [2-5]). The dataset of the 2009 campaign consist both IC and CG video recordings. In the case of $\mathrm{CG}$ flashes, most were downward negative. Only two upward CG flashes and one downward positive flash were recorded.

\subsection{Downward negative CG flashes}

Figure 2 shows a stacked image of video frames of a downward negative CG flash. In the composition, the saturated frames corresponding to the return stroke have been removed.

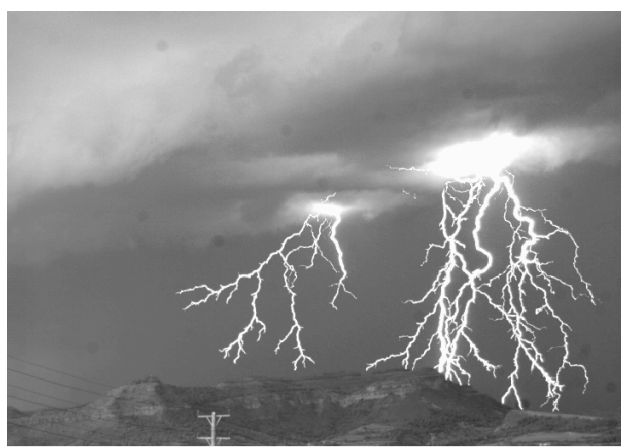

Figure 2. Staked images of a downward -CG flash. The total duration of the flash is $404.1 \mathrm{~ms}$.

As seen in many videos, the flash starts with several simultaneous leaders towards the ground with similar speeds. These leaders can be separated few kilometers, but supposedly, these are branches from the same origin within the cloud.

As mentioned, typical observed downward -CG flashes start with several leaders moving down at similar speeds. The total number of branches increases as leaders approach to the ground. At $10000 \mathrm{fps}$ these leaders appear to progress continuously. All leader tips produce luminosity but not all the channels have the same luminous intensity. As a rule, the channel(s) that will touch the ground the first and produce a path for the return stroke generate more light than the others. At subframe times $(\leq 100 \mu \mathrm{s})$ very fast leaders progressed relative long distances and disappear. These fast events are considered as recoil leaders (RL). After the return strokes, in some videos, dart leaders illuminate fast the previous channels before subsequent return strokes. However, in some cases dart leaders illuminate a long portion of previous channels, while finally don't reach the ground. Frequently, new stepped leaders toward the ground appear between strokes. In some cases these leaders produce a new return stroke at locations very close (or the same) as first return strokes. Continuing currents and superimposed surges in luminosity have also been observed.

\subsection{Downward positive CG flashes}

In the observed lightning flashes, the downward positive ones were easy to distinguish due to its particular behavior. Figure 3 displays an image of stacked video frames of a downward positive CG flash.

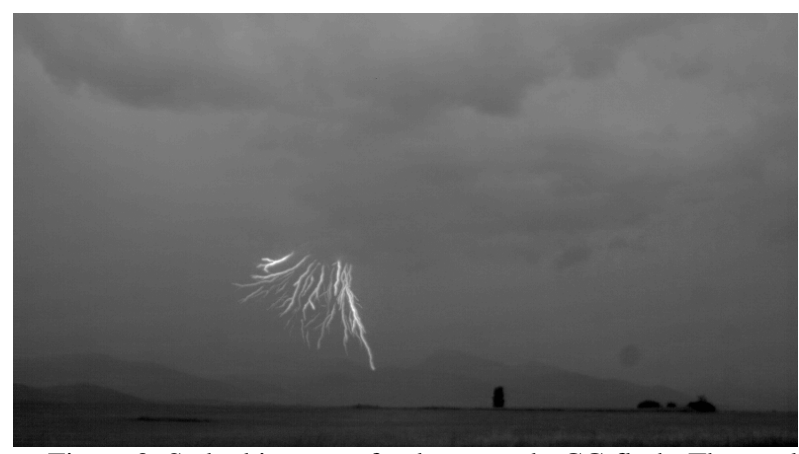

Figure 3. Staked images of a downward +CG flash. The total duration of the flash is $83.2 \mathrm{~ms}$.

As pointed by some authors before (e.g. [3]) the development of positive leaders in CG proceeds much differently from negative leaders. In the recorded videos, portions of the leaders appeared illuminated during only one frame $(\leq 100 \mu \mathrm{s})$. We suppose these to be recoil leaders (RL). In few cases the RL remained illuminated for more than one frame showing luminosity moving from the tip of the visible channel up to the cloud. In our observations we only were able to observe RL and not continuous leader propagation. Note in figure 3 the tending curl to the left of some leaders, the rightmost leader produced the return stroke. 


\subsection{Upward CG flashes}

Among the videos recorded in the campaign only two corresponded to upward flashes. In the particular case of the event in figure 4, two upward flashes were simultaneously produced.

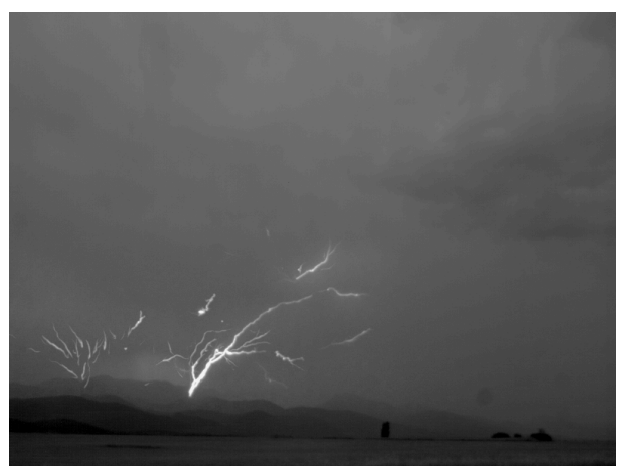

Figure 4. Stacked images of two simultaneous upward flashes. The total duration of the flash is $343.6 \mathrm{~ms}$.

In the observed upward flashes no return stroke was produced. Only transient luminosity appeared suddenly illuminating some parts of the channel. In the case of figure 4, an upward leader (right event) started continuously propagating upward just after the cloud was illuminated. The leader presented only few branches. Superimposed to these branches very fast events occurred producing intense illumination of channels especially in the base sections. While in the rightmost event the branches were continuously illuminated, the upward leaders of the leftmost event looked as disconnected fast illuminated portions such of RL. We believe that both events were upward positive leaders that transferred negative charge to ground.

\section{DETECTIONS OF THE XDDE AND LINET}

Thanks to the high time accuracy in the frame stamping of video, the question of what is displayed in the screen at the time of detection is raised. The time and location of the intra-cloud (IC) VHF sources obtained by the interferometric network (XDDE) and the locations provided by the VLF network (LINET) are compared with the videos of their corresponding flash. The aim here is not to compare which network detects more lightning or locates better, but to determine which lightning process is detected. Before, one would expect to see that the VHF interferometers (XDDE) detect mostly recoil events of IC flashes and strongly radiating negative leaders [11]. For the VLF network (LINET) we expected to detect return stroke currents of CG flashes and IC flashes with high currents and neutralized charges.

\subsection{Detections of IC flashes}

Figure 5 shows four frames of an IC flash recorded on the October $1^{\text {st }}, 2009$. The first visible light associated with the flash appeared at 16:59:58.073227 UT. At 16:59:58.073526 UT (figure 5a) a very bright light saturated the camera. At this moment LINET got a detection classified as IC with $-23 \mathrm{kA}$ of estimated current amplitude. There were no detections in the VHF network. The intense luminosity lasted for $2.5 \mathrm{~ms}$ indicating important charge transfer. After that, visible leaders started to propagate in all directions at the cloud base (e.g. figure 5b). These leaders stop at 16:59:58.256 UT. During these moving leaders none of both networks offered detections. At 16:59:58.256 UT (figure 5c) again a very bright light saturated the camera similar to figure 5a. This event was reported by both networks. It was classified as IC by LINET with a peak current of 11.2

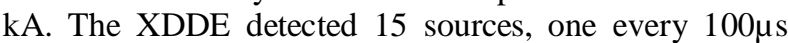
until 16:59.58.2615 UT (figure 5d). During this period the visible channel was continuously illuminated. From our videos we conclude that the IC detections reported by the LINET corresponded to big charge neutralizations in the cloud with durations up to few milliseconds. The level of image saturation produced was similar to those produced by return strokes in CG flashes. This result is consistent with the VLF frequency range where the LINET is sensing. In other hand, the XDDE started to report a burst of sources when a visible leader was permanent intense illuminated for $1.5 \mathrm{~ms}$. The XDDE is limited to a time resolution of $100 \mu \mathrm{s}$. With such limitation it is difficult to compare the type of detections with those measured with a similar interferometer in [11]. In that work, two types of emissions where observed: low-rate pulsed emissions and burst of pulses. The first type corresponded to rates below 20 pulses/ms while the burst lasted from several hundred microseconds to a few milliseconds. The low-rate type were associated with important IC charge transfers while the burst were associated with highly organized propagation of sources in the $10^{7} \mathrm{~m} \mathrm{~s}^{-1}$. It is difficult to classify the IC observations here, but from the changes measured by means of the electric field antenna and the illumination of the visible channel, the low-rate type seems to be the phenomenon associated with IC detections. However the charge transfer mode associated with the low-rate pulses would be different to the other associated with the ones where LINET got detections. 


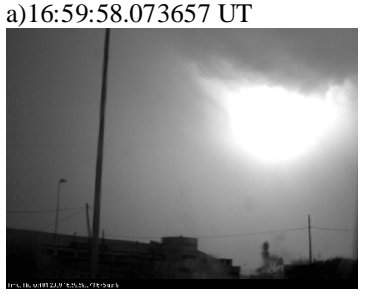

c) $16: 59: 58.256342 \mathrm{UT}$
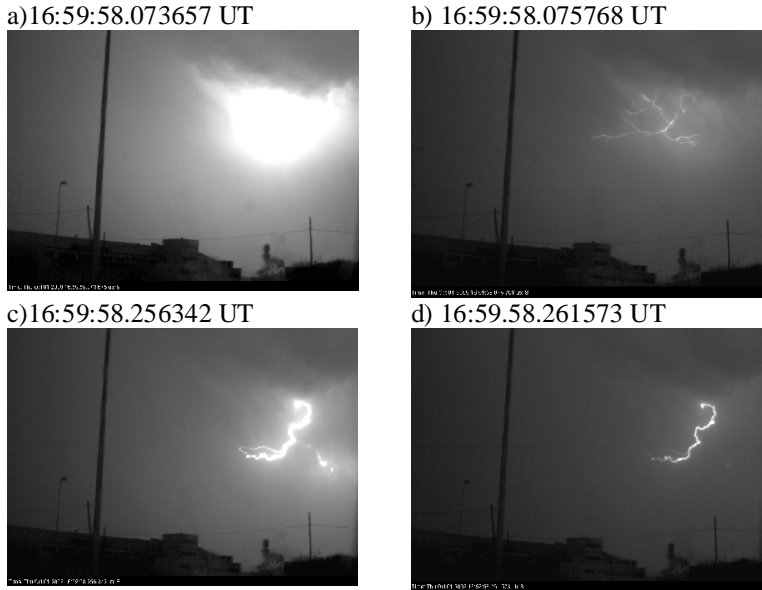

d) $16: 59.58 .261573$ UT

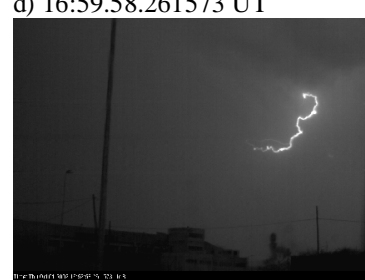

Figure 5. Four frames of an intra-cloud lightning produced on October $1^{\text {st }}, 2009$ at 16:59:58 UT.

Regarding detection efficiency of the recorded IC flashes the XDDE detected mostly at least one VHF source for of all the IC flashes, while LINET detected $85 \%$ of the flashes seen by video. LINET provided a maximum of 4 detections per IC flash and, in few cases, some detections where classified as CG.

\subsection{Detections of CG flashes}

Detections of CG flashes by means of the XDDE were compared with high-speed videos in [7]. The comparison showed that most of the detections usually appear few milliseconds before the appearance of a visible leader in a common negative downward CG flash. As described before, during the campaign, the XDDE was composed of two types of detectors. Then, as mentioned in [7] the network performance (efficiency and location accuracy) drastically changed between different territory areas. As result the $\mathrm{CG}$ flash detection efficiency in the whole observation area was $68 \%$. Nowadays the XDDE has upgraded all detectors to LS8000 and the CG flash detection efficiency is expected to be higher.

In the case of detections reported by the LINET all of them agree with the time when the return strokes occurred (normally the camera saturated). Also good location accuracy was found in all of the flashes. As result of flash detection, the network detected all the observed flashes (flash detection efficiency equal to 100 $\%$ ) and, regarding stroke detection efficiency it was higher than $75 \%$.

\section{ANALYSIS OF HIGH-ENERGY DETECTIONS}

$\mathrm{X}$-ray emissions from thundercloud and lightning flashes have been reported during last decades. But it was not until 2001[12] when the authors showed the production of energetic radiation during natural lightning. In other hand, the detection of surprisingly energetic terrestrial gamma-rays (TGFs) from space (BATSE and RHESSI) (E.g.[9]) raised interest of the scientific community regarding their origins. Lightning has been proposed to be the source, as several studies (e.g. [14-15] were able to relate TGFs to cloud-to-ground lightning flashes. During our 2009 campaign we also focused on measuring highenergy detection from natural lightning with a $\mathrm{NaI}(\mathrm{Tl}) / \mathrm{PMT}$ detector. From the sixty recorded flashes only one produced detectable high energy emissions.

Figure 6 shows the detector output and the electric field. The stroke at the figure did not present the common features of other observed flashes. A very fast leader was identified in a period of 2 seconds without any other lightning activity. The lightning struck very close to the measurement location but unfortunately it was not in the direction of the camera. However in the videos we can watch some scattered light that matches with the leader and return stroke. The burst of high-energy detections was produced during the leader phase and few after the return stroke. The observation is very similar to those reported in [12]. Most of the detections occurred $0.6 \mathrm{~ms}$ before the return stroke but, unfortunately the detector saturated in most of the detections indicating energies over $180 \mathrm{keV}$.

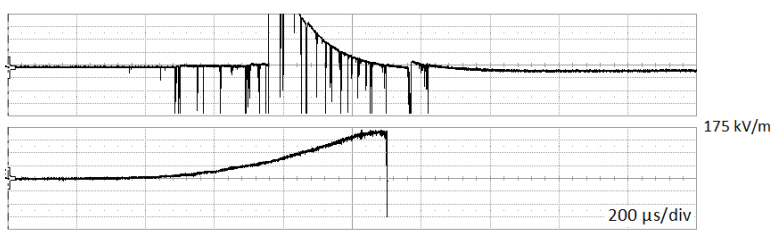

Figure 3. High-energy detections (top) and electric field of a very close lightning (bottom).

\section{CONCLUSIONS}

The paper highlighted the results of the 2009 campaign. As novelty in this campaign high-high speed video and high-energy detections have been added to our common instruments.

The paper summarized the optical differences of different type of cloud-to-ground lightning flashes. The propagation of negative and positive leaders still presents research challenges such as the presence of recoil leaders.

Thanks to the precise time synchronization of each video frame we investigated which processes are detected the XDDE network (VHF) and the LINET (VLF). We 
observed that the XDDE detects mostly those processes of intra-cloud flashes where substantial charge is transferred during few milliseconds. The study of the detections of intra-cloud events provided by the LINET were related to high and fast (less than a millisecond) charge transfers within the cloud that saturated the camera in the same manner as return strokes in cloud-toground flashes.

To conclude, the burst of high-energy detections related to a stepped leader of a negative cloud-to-ground flash have been presented. We have been able to detect emissions from a very close flash indicating the difficulty of measuring these detections in flashes at distances close than $500 \mathrm{~m}$.

Acknowledgments: This work was supported by the Spanish MICINN grants ESP2007-66542-C04-02 and AYA 2009-14027-C05-05. We would express our thanks to the Meteorological Service of Catalonia for providing to XDDE and radar data and also to nowcast $\mathrm{GmbH}$ and Fulgura S.L. for providing LINET data.

\section{REFERENCES}

[1] Montanyà , J., et al. , "High-speed intensified video recordings of sprites and elves over the western Mediterranean Sea during winter thunderstorms", J. Geophys. Res., 115, A00E18, doi:10.1029/2009JA014508, 2010.

[2] M. M. F. Saba, M. G. Ballarotti, and O. Pinto, "Negative cloud-to-ground lightning properties from high-speed video observations", J. Geophys. Res., 111, D03101, doi:10.1029/2005JD006415, 2006.

[3] M.F. Marcelo Saba, Kenneth L. Cummins, T.A. Warner, E. Philip Krider, Leandro Z. S. Campos, Mauricio G. Ballarotti, O. Pinto Jr., and A. Stacy A., Fleenor, "Positive leader characteristics from high-speed video observations", GEOPHYSICAL RESEARCH LETTERS, VOL. 35, L07802, doi:10.1029/2007GL033000, 2008.

[4] M. M. F. Saba, L. Z. S. Campos, E. P. Krider, and O. Pinto, "High-speed video observations of positive ground flashes produced by intracloud lightning", Geophys. Res. Lett., 36, L12811, doi:10.1029/2009GL038791, 2009.

[5] M. G. Ballarotti, M. M. F. Saba, and O. Pinto, "High-speed camera observations of negative ground flashes on a millisecond-scale", Geophys. Res. Lett., 32, L23802, doi:10.1029/2005GL023889, 2005.

[6] Kehoe, K.E. and E.P. Krider, "NLDN Performance in Arizona", in Proc. 18th Internat. Lightning Detection Conf., Helsinky, Finland, 2004.

[7] J. Montanyà, N Pineda, G. Solà, O. van der Velde, D. Romero and D. Aranguren, "Comparison between high-speed video recordings of lightning and the detections of the Catalan Lightning Location Network (XDDE)”, 21 st Internat. Lightning Detection Conf., Orlando, US, 2010.

[8] N. Pineda, and J. Montanyà, "Lightning Detection in Spain: The Particular Case of Catalonia." In "Lightning: Principles, Instruments and Applications". Eds. H.-D. Betz, et al., Springer. 461 p. ISBN: 978-1-4020-9078-3,2009.

[9] H. D. Betz, T. C. Marshall, M. Stolzenburg, K. Schmidt, W. P. Oettinger, E. Defer, J. Konarski, P. Laroche, and F. Dombai, "Detection of in-cloud lightning with VLF/LF and VHF networks for studies of the initial discharge phase", Geophys. Res. Lett., 35, L23802, doi:10.1029/2008GL035820, 2008.

[10] Mazur, V., E. Williams, R. Boldi, L. Maier, and D. Proctor, "Initial comparison of lightning mapping with operational Time-Of-Arrival and Interferometric systems", J. Geophys. Res., 102(D10), 11071-11085, 1997.

[11] Richard P., A. Delannoy, G. Labaune and P. Laroche, "Results of spatial and temporal characteristics of the VHF-UHF radiation of lightning”, J. Geophys. Res., 91, 1248-1260, 1986.

[12] C.B Moore, K. B. Eack, G. D. Aulich, and W. Rison, "Energetic radiation associated with lightning stepped-leaders", Geophys. Res. Lett., 28, 2141-2144, 2001.

[13] J. R. Dwyer et al., "X-Ray bursts associated with leader steps in cloud-to-ground lightning", Geophys. Res. Lett., 32, doi: 10.1029/2004GL021782, 2005.

[14] G.J. Fishman, et al., "Discovery of intense gammaray flashes of atmospheric origin", Science, $264,1313,1994$

[15] U.S. Inan, S. C. Reising, G. J. Fishman, and J.M. Horack, "On the association of terrestrial gammaray bursts with lightning and implications for sprites", Geophys. Res. Lett., 23, 1017-1020, 1996. 